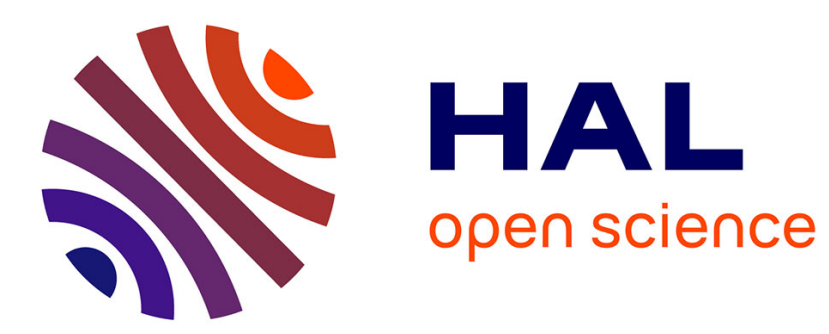

\title{
Conceptual Design of an Intelligent Welding Cell Using SysML and Holonic Paradigm
}

\author{
Abdelmonaam Abid, Maher Barkallah, Moncef Hammadi, Jean-Yves Choley, \\ Jamel Louati, Alain Riviere, Mohamed Haddar
}

\section{To cite this version:}

Abdelmonaam Abid, Maher Barkallah, Moncef Hammadi, Jean-Yves Choley, Jamel Louati, et al.. Conceptual Design of an Intelligent Welding Cell Using SysML and Holonic Paradigm. Sixth International Congress on Design and Modeling of Mechanical Systems, Mar 2015, Hammamet, Tunisia. 10.1007/978-3-319-17527-0_1 . hal-01330195

\section{HAL Id: hal-01330195 \\ https://hal.science/hal-01330195}

Submitted on 10 Jun 2016

HAL is a multi-disciplinary open access archive for the deposit and dissemination of scientific research documents, whether they are published or not. The documents may come from teaching and research institutions in France or abroad, or from public or private research centers.
L'archive ouverte pluridisciplinaire HAL, est destinée au dépôt et à la diffusion de documents scientifiques de niveau recherche, publiés ou non, émanant des établissements d'enseignement et de recherche français ou étrangers, des laboratoires publics ou privés. 


\title{
Conceptual design of an intelligent welding cell using SysML and Holonic paradigm
}

\author{
Abdelmonaam ABID ${ }^{1}$, Maher BARKALLAH ${ }^{1}$, Moncef HAMMADI ${ }^{2}$, Jean- \\ Yves CHOLEY ${ }^{2}$, Jamel LOUATI ${ }^{1}$, Alain RIVIERE ${ }^{2}$, Mohamed HADDAR ${ }^{1}$ \\ ${ }^{1}$ National School of Engineers of Sfax (ENIS), B.P, 1173, 3038 Sfax, Tunisia \\ abidmonom@gmail.com, bark_maher@yahoo.fr, louati.ttg@gnet.tn, \\ mohamed_haddar@yahoo.fr \\ ${ }^{2}$ High Institute of Mechanics of Paris (SUPMECA), 3 rue Fernand Hainaut 93407, Saint- \\ Ouen Cedex, France \\ $\underline{\text { moncef.hammadi@supmeca.fr, jean-yves.choley@supmeca.fr, alain.riviere@supmeca.fr }}$
}

Abstract. Manufacturing companies are more and more required to implement intelligent infrastructures to handle the dynamic nature of demands and make quick decisions. Very limited research has been reported on holonic control in a flow-line type manufacturing systems such as welding cells.

In this paper we present a conceptual design of an intelligent welding cell using SysML (Systems Modeling Language). The holonic paradigm has been adopted to check the different configurations desired by the customers, which allows users to pre-define and pre-design the different configurations of the welding cell. The topdown modeling method based on SysML and the holonic control paradigm allows designers to define the different requirements of the manufacturing system and generate the appropriate dynamic configurations without complicating the design process. The approach has been applied to the case of a welding cell of the remedial parts of scaffolding systems. The objective in this case is to adapt the manufacturing system to the client needs for using either cylindrical or oval cross sectional traverse parts, and therefore to respond to the manufacturing company needs in terms of flexibility and productivity.

Keywords: Reconfigurable manufacturing systems; Holonic paradigm; SysML; Welding cell;

\section{Introduction}

Manufacturing systems need to handle the dynamic nature of demands. For this purpose companies must implement an intelligent infrastructure to make quick decisions in order to adapt in real time to internal and external variability production. As a result, companies require assuring a product with high quality at lower costs and with short life cycles. 
In this paper, we aim to provide a holonic paradigm for controlling and designing of a welding cell and to adapt the production with the client trends in which System Modeling Language (SysML), is adopted as a means to integrate and organize the hierarchy of models necessary to describe all the aspects of the system and describe the requirements of the client.

There are many publications on designing manufacturing systems but only few concentrate on adopting the design phase with the client trends. In one of the first papers on the subject (Dazhong Wu et al. 2011) proposed to support variety management decisions, by implementing the SysML-based information models as a variety coding information system in a case study of switchgear which enclosure production reconfiguration system .A second paper proposes an approach to verify complex systems using SysML as a language which describes the system structure and requirements. Authors demonstrate this methodology be using a factory automation system (Marcos V. Linhares et al. 2007).

We will show how it is possible to exploit SysML for establishing clear relationships among different configurations, consequently, for obtaining a comprehensive and coherent representation of a manufacturing system. In order to show the effectiveness of the holonic approach proposed in the paper.

This paper is structured as follows. Section 2 presents the case-study of a welding cell. Then, a SysML model for production reconfiguration is proposed in section 3 . A holonic paradigm is detailed in section 4 . Finally, section 5 presents our conclusion.

\section{$2 \quad$ Case-study of a welding cell}

\subsection{Definition of shoring tower}

The shoring tower system as represented the (figure. 1) has been developed to meet the requirements of the modern construction industry in terms of speed, safety and profitability. 


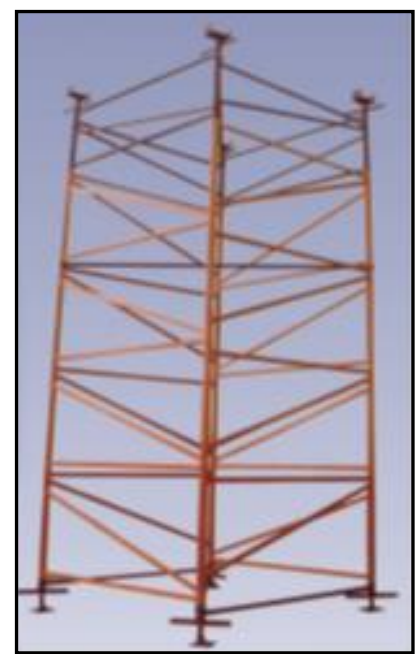

Fig. 1 Shoring tower-configuration

The remedial article is a part in the shoring tower, in our case the welding cell should produces this article with integrating the re-configuration and the flexibility while introducing a controlling concept to validate the different configurations.

\subsection{The Remedial Article}

The final product shown in (Figure 2) of the welding cell is the remedial article. Two configurations of the remedial articles are considered, with traverse (3) either with cylindrical cross section or with oval cross section, depending on the customer needs. For this reason the welding cell process should be adapted with these two configurations.

Table 1: shows the characteristics of both configurations.

\begin{tabular}{lllll}
\hline Reference & Form & Diameter & Thickness & Length \\
\hline 1 & Cylindrical & $40 \mathrm{~mm}$ & $2 \mathrm{~mm}$ & $135 \mathrm{~mm}$ \\
2 & Cylindrical & $48.3 \mathrm{~mm}$ & $2.5 \mathrm{~mm}$ & $125 \mathrm{~mm}$ \\
3 & Cylindrical & $33.7 \mathrm{~mm}$ & & \\
& Oval & $30 \mathrm{~mm}$ & $2 \mathrm{~mm}$ & $1452 \mathrm{~mm}$ \\
\hline
\end{tabular}




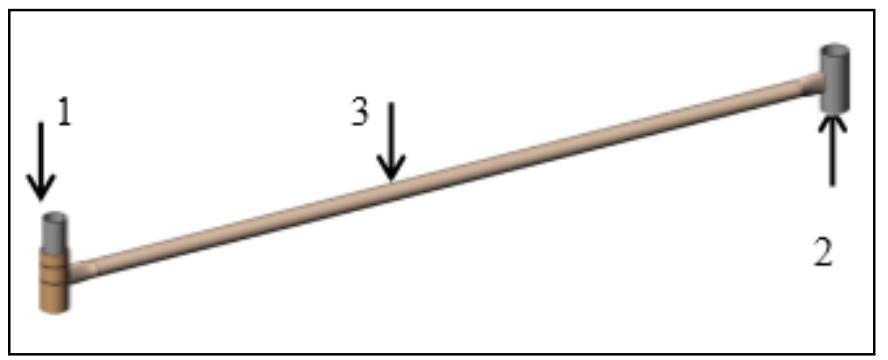

Fig. 2. 3-D layout of the remedial article

(Figure. 2) shows the 3-D geometry and the three parts to be welded to make the remedial article. The welding machine should therefore weld these three components which have the different characteristics cited in (table 1) with respect to the specifications imposed.

\section{A SysML model for production reconfiguration}

The development of the information model for the production reconfiguration system poses many challenges. Modeling requirements and structure can provide a robust system description. Therefore, the SysML (Tim Weilkiens 2007) based information model for production reconfiguration consists of requirements analysis and structural analysis.

Requirements analysis defines the hierarchy of requirements and interrelationships among requirements. Concerning the structural analysis it represents the elements of the production reconfiguration.

\subsection{Requirements analysis}

The requirements diagram indicates all the capabilities or conditions that a system must satisfy. A requirement can be decomposed into sub-requirements, so that multiple requirements can be organized as a tree of composite entities. Each requirement is supposed to have an id (unique) and a text parameter, which contains its description. Requirements are essential in the validation step, so particular care must be taken in handling them.

A requirement specifies a condition that must be satisfied, a function that a system must perform, or a performance level that a system must achieve. Requirements 
come from many sources, such as customers, designers, process engineers, or organizations; (Figure 3) shows a requirement diagram of production reconfiguration system. This example highlights a number of different requirements relationships, including satisfy, derive and containment. For example, the satisfy relationship is used to assert that variety decisions satisfy the requirements of minimum production costs and minimum lead time. The derive relationship between a source requirement, customer needs, and the derived requirements, minimum production costs and minimum lead time, is established based on marketing analysis. Similarly, the requirement of production reconfiguration is derived from the requirements of minimum production costs and minimum lead time, based on production reconfiguration principle. The containment relationship represents how complex production reconfiguration requirements can be partitioned into a set of lower-level requirements For instance, the requirements of production reconfiguration contain three requirements associated with fixture system and parameters of welding and part 3 of the product.

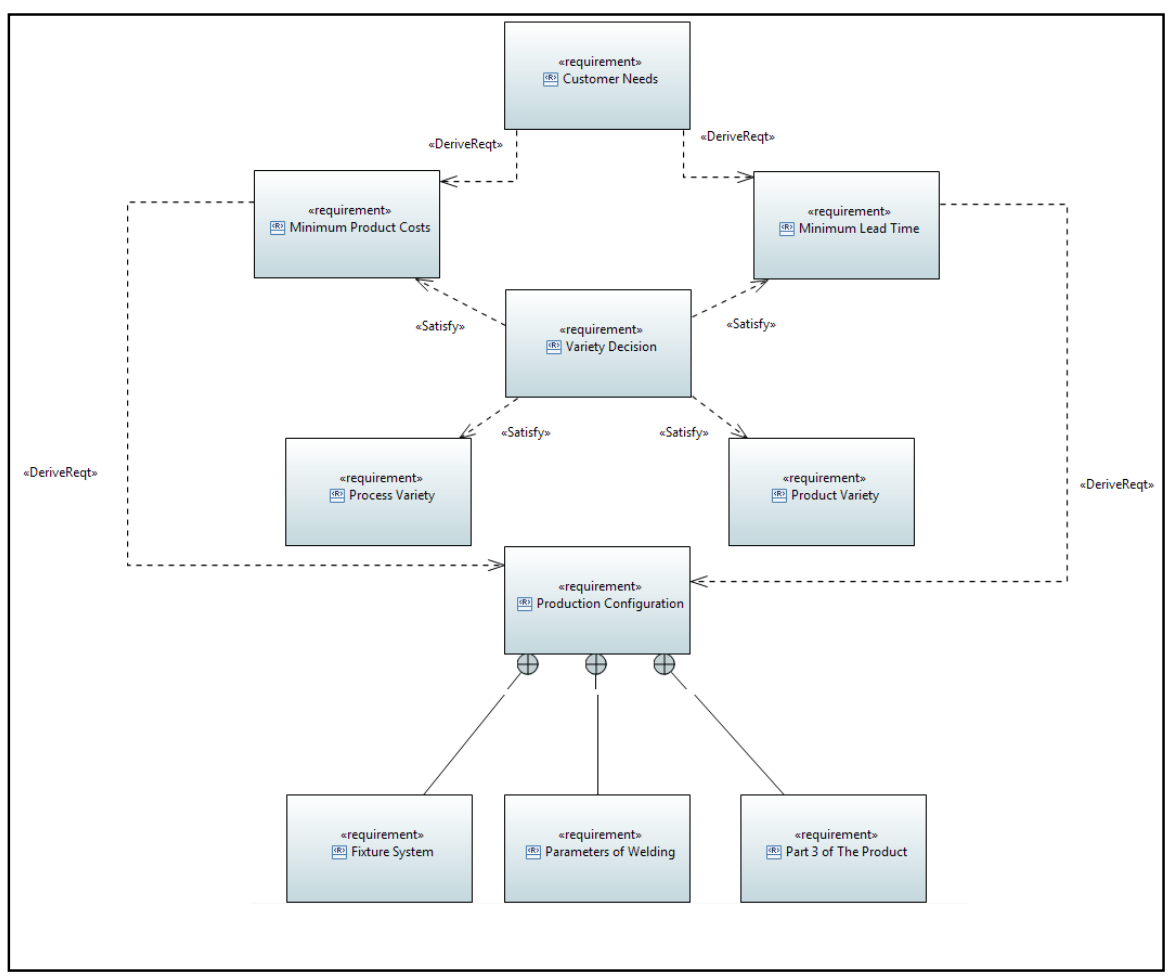

Fig. 3 SysML requirements diagram for production re-configuration 


\subsection{Structural analysis}

In software systems, the taxonomy that generates the division of the system into modules is contained in the class diagram, which contains the "building blocks" that implement the system functionality and whose interaction will determine the system architecture. SysML extends the concept of class to that of block, which is a composite structure endowed with an interface suitable to describe the architecture of a physical system. Structural information about blocks is contained in the block-definition diagram; for our validation procedure, we shall take into account only a limited number of relationships among the possible associations defined in the standard, namely the UML composition, aggregation, and association.

(Figure 4) shows the structure analysis of the welding cell using a block definition diagram. In the context of production system, a block in SysML can represent any entity (e.g., part, function or operation). By including a number of blocks, a block definition diagram can define the hierarchy of the system of interest in terms of its structural feature and the relationships between the blocks. The welding cell structure consists of conveyor A, conveyor B, conveyor C part, Robot, welding machine, and conveyor D. To explain the BDD, the conveyor A, B and C are associated with a robot in order to load the different parts transported via the conveyors into the welding cell. After the welding operation made by the welding machine the Robot unload the final product, in this case the product with oval section cross or with cylindrical section cross, into the conveyor D to the stock.

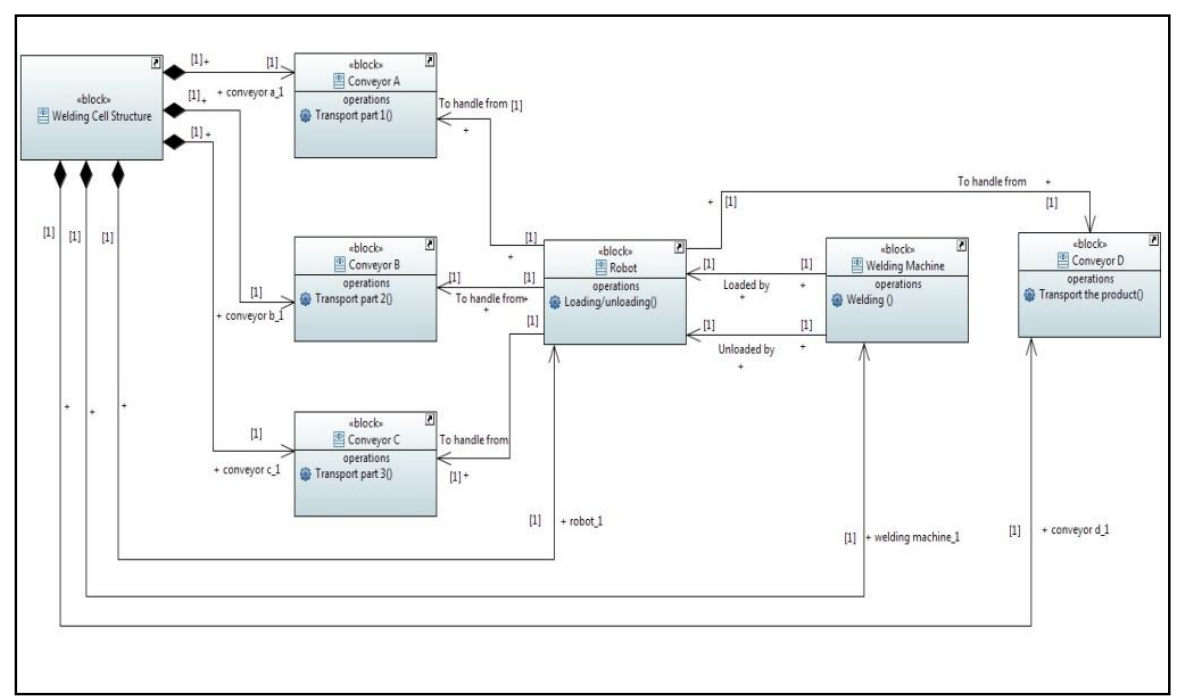

Fig. 4 SysML block definition diagram for welding cell structural model 


\subsection{Results}

A SysML model is developed to formally represent the requirements and structure of the welding cell including production reconfiguration. It enables the system to share and exchange information among multiple domains in a multi-disciplinary team by ensuring semantic coherence along the entire design chain, keeping the traceability across levels of abstraction, and improving the interoperability among tools. Moreover, it supports trade-off analysis to evaluate production performance and costs by combining with other execution environments.

For controlling the SysML model during the pre-design phase, we propose the holonic paradigm for controlling and organizing the welding cell modeled by SysML in order to validate our model.

\section{Holonic paradigm}

Holonic paradigm support the use of autonomous and cooperative manufacturing units called holons, organized in a flexible hierarchy in order to increase the agility and re-configurability of the manufacturing process. Manufacturing systems are becoming more and more complex and the development of many researchers are working for finding new paradigm solutions for managing and controlling this complexity which was modeled by different language in order to include re-configurability and flexibility of the production system.

The holonic paradigm (Jo Wyns 1998) can identify the types of holons necessary for any manufacturing system, its responsibilities, and the interaction structure in which they cooperate. The holonic architecture is made up of three basic holons, order holon, product holon, and resource holon, extended with the concept of staff holon. These holons are specified using object-oriented concepts such as aggregation and specialization. Each of the basic holons is responsible for one of the following manufacturing controlling aspects: internal logistic, manufacturing scheduling, and resource management. A resource holon has a physical part and an information processing part that controls the resource; it combines the information of a physical device and the ability to control this device. The resource holon resembles the concept of class in Object-Oriented technology. A product holon stores the process and product knowledge needed to insure the correct manufacture of the product. It acts as an information server for the other holons in the HMS (P. Valckenaers et al. 1996). An order holon represents a task in a manufacturing system. It is responsible for doing the work assigned on time and in the right way. It 
manages the physical products that are being produced, the product status models, and all the logistic processing information related to the task. Order holon is in charge of production scheduling and control. It schedules the task progress after synthesizing the knowledge of process and configuration supplied by product holon and configuration holon respectively, triggers process execution properly according to the type of products, monitors the whole progress to find system deadlock and handle it in. With the interactions between them, all the holons generate mutually acceptable scheme and accomplish it in order to fulfill system goal because autonomy is one of its main characteristics, which means each holon is able to create a plan and execute it independently.

The welding cell as shown in (figure 5) is composed of the three base holons

- Resource holons represent the physical devices. In our cases resource holons are the conveyors systems (A, B, C and D), the welding machine (5), the fixing systems (7FO and 7FC) and the gantry robot (4).

- Product holons represent the product to weld (8). In our case they are containers for information about the remedial article to be welded.

- Order holons are generated for each request. They are the driven agenda of the holonic system. They compete or collaborate with each other to configure the welding cell and ensure the appropriate parameters.

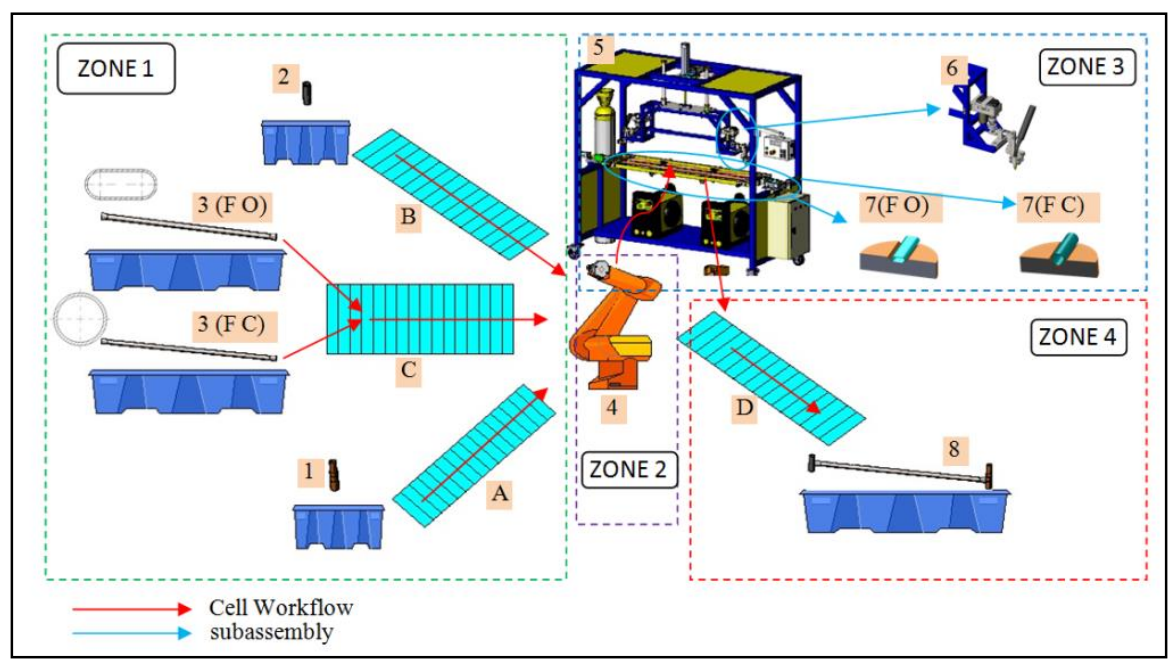


Fig. 5 Structure of the welding cell describing the holonic paradigm

\subsection{Results}

A "top-down" technique used to decompose the welding cell from a design specification to basic levels. The holonic approach allows to model at different levels of abstraction system. The hierarchical organizational decomposition of a system can be refined up to the level where the designer considers the complexity of the behavior is sufficiently low for immediate implantation.

\section{Conclusion}

In this paper, we proposed an approach to design a welding cell based on SysML language to formally represent the requirements and structure of the welding cell including production reconfiguration while this design was controlled by the holonic paradigm in order to decompose the welding cell from a design specification to basic levels. The presented approach allows designers to integrate client trends and helps them in validating the design and making decisions efficiently.

\section{References}

Dazhong Wu • Linda L. Zhang · Roger J. Jiao · Roberto F. Lu (2011). SysML-based design chain information modeling for variety management in production reconfiguration. J Intell Manuf (2013) 24:575-596. DOI 10.1007/s10845-011-0585-6

Marcos V. Linhares, R^omulo S. de Oliveira, Jean-Marie Farines (2007). Introducing the Modeling and Verification process in SysML. 1-4244-0826-1/07/\$20.00 @ 2007 IEEE

Tim Weilkiens (2011). Systems Engineering with SysML/UML: Modeling, Analysis, Design. ISBN 0080558313, 9780080558318

Jo Wyns, Paul Valckenaers, L.B.P.P. (1998). Reference architecture for holonic manufacturing systems: Prosa. Computers in Industry, 37(3), 255274

P. Valckenaers, H. Van Brussel, L. Bongaerts, J. Wyns (1996). Holonic Manufacturing Systems. DOI: 10.3233/ICA-1997-4304 